\title{
J. J. BENEGASI Y LUJÁN EN SUS IMPRESOS: LA CONSTRUCCIÓN DE UN PERFIL POLIÉDRICO
}

\author{
The Published Works of J. J. Benegasi y Luján: \\ the Construction of a Polyhedric Profile
}

\author{
Tania PADILLA AGUILERA \\ Universidad de Córdoba \\ 152paagt@uco.es
}

Fecha de recepción: 11/09/2018

Fecha de aceptación definitiva: 21/02/2019

RESUMEN: La consagración de José Joaquín Benegasi y Luján (1707-1770) como autor profesional es el resultado de un periplo literario y vital cuyas huellas nos proponemos rastrear en la trayectoria de sus obras publicadas y a partir del concepto de firma autorial. Los privilegiados contactos académicos, la influencia de la figura paterna y una situación económica no demasiado boyante animan a nuestro autor a recorrer el arduo camino desde el amateurismo hasta la profesionalidad literaria. Sin embargo, es en el período final de su carrera cuando encontramos la presencia de un discurso más personal en el que abunda la autorreferencialidad y en el que se consolidan esas características que el autor ya ha asumido como propias (estilo jocoserio, arte menor). Partiendo de estas marcas identitarias intentaremos establecer los puntos clave de la estrategia editorial de Benegasi en relación con la construcción de su propio perfil autorial.

Palabras clave: amateurismo; firma autorial; profesionalización; impresos; mercado editorial; siglo XVIII.

ABSTRACT: Recognition of José Joaquín Benegasi y Luján (1707-1770) as a professional author is the result of his distinctive life and literary career. This paper proposes to identify the signature literary characteristics that define his published works. Benegasi y Luján was inspired to traverse the arduous road from amateurism 
to literary professionalism by his privileged academic contacts, his father's influence and a hardly affluent economic situation. However, it is in the final period of his career that we find the presence of a more personal discourse in which selfreferentiality is plentiful and the characteristics he perceived as his own (jocoserio style, verse in arte menor) are consolidated. Based on these identifying marks, the paper undertakes to define the key aspects of Benegasi's editorial strategy as he constructed his own profile as an author through a unique process of self-fashioning.

Key words: amateurism; signature; professionalization; published works; editorial market; $18^{\text {th }}$ century.

José Joaquín Benegasi y Luján (1707-1770) firmaba sus impresos, especialmente los publicados durante su etapa de juventud, con seudónimos en los que utilizaba alguno de los apellidos de su casa combinados con su nombre de pila: "Joaquín del Rosal», "Joaquín Maldonado» o "Joaquín de Paz y Monroy». Solo en un caso empleó un nombre que no tenía que ver directamente con su persona: "Juan Antonio Aspitarte», el nombre de su criado, quien parece ser que hizo para él algunas labores de transcripción, por lo que muy probablemente se trata del autor material de las obras firmadas bajo este identificativo.

El uso de los seudónimos era habitual en la primera mitad del siglo XVIII, ya que hasta los años 60 no entran en vigor las nuevas leyes de responsabilidad legal y moral decretadas durante el reinado de Carlos III (1759-1788) ${ }^{1}$. Por otra parte, el perfil de José Joaquín Benegasi y Luján responde a la perfección al del autor que frecuentaba este tipo de práctica editorial: era un magistrado perteneciente a la "baja" nobleza que encuentra en el arte menor y el estilo jocoserio su voz identitaria. Si seguimos las tesis de Jiménez Belmonte ${ }^{3}$, Benegasi se presenta con un papel claramente amateur en el campo literario español de la época, aunque, como veremos, modificará este rol a medida que vaya saliendo airoso, y en algunas ocasiones incluso triunfante, en sus diferentes tentativas literarias -algunas de ellas considerablemente arriesgadas-, que encontrarán su hueco en el complejo mercado de la época a través de una calculada estrategia editorial.

1. Se aborda el complejo asunto del control político del libro durante el reinado de este monarca en el capítulo xviii de Agullar PIÑal, Francisco. Madrid en tiempos del "mejor alcalde». Sant Cugat (Barcelona): Editorial Arpegio, volumen 3, 2016. A propósito de la legislación vigente en la época, véase la Novísima reco pilación de las leyes de España (1805), libro VIII.

2. Colocamos este término entre comillas porque, al menos en el caso del padre de nuestro autor, podría hablarse de su encuadre en una nobleza "media", debido a la enorme cantidad de títulos que acumulaba, algunos de los cuales transmitió a su hijo. No obstante, no todos los cargos de regidores se transmitían por la sangre; como veremos más adelante, estos podían adquirirse.

3. JimÉnEz Belmonte, Javier. "Amateurs preclaros de la España postbarroca: nostalgias de un modelo socioliterarion. Caliope: journal of the Society for Renaissance and Baroque Hispanic Society, 2012, vol. 18 , n. ${ }^{\circ}$ 1, pp. $78-101$. 
El empleo del seudónimo por parte de Benegasi adquiere un carácter sintomático en el examen diacrónico de su producción editorial. Mientras que su presencia es constante en su producción de juventud -en aquellas obras publicadas en la década de los 30-, en la producción posterior únicamente encontramos el enmascaramiento de la firma autorial en aquellas obras que parecen alejarse de la línea estilístico-formal escogida por el autor ${ }^{4}$ para conformar lo que tanto él mismo como sus lectores comienzan a reconocer como una trayectoria literaria propia. Así, a partir de los años 40 el autor firma bajo seudónimo obras como comedias, epístolas o pronósticos, tal y como veremos más adelante.

La conquista de la firma autorial en Benegasi está estrechamente vinculada a la asunción y posterior exhibición de una genealogía familiar que, por una parte, persigue recuperar los vínculos de sangre, principalmente de la rama de los Luján, de reconocido abolengo, sobre todo en relación con la ciudad de Madrid y su fundación, y por la otra, y quizá de una forma más relevante, reactivar una tradición literaria: José Joaquín trata de seguir los pasos de su padre, el también poeta, y además dramaturgo, Francisco Benegasi y Luján (1656-1743), entre cuyas producciones destacan numerosas composiciones en arte menor, como romances o seguidillas. En relación con la recuperación de esta genealogía literaria, cabe destacar la asunción del apellido paterno Benegasi ${ }^{5}$ por parte de nuestro autor, mientras que el membrete que indefectiblemente acompaña a su firma ("Señor de Terreros y Valdeloshielos, regidor perpetuo de la ciudad de Loja") podría apuntar a la señalada recuperación de la estirpe familiar. Cabe suponer que entre ambas, que el autor aplica a la causa literaria, se establece una relación de interdependencia que simultáneamente las acrecienta y que, en cualquier caso, redunda en la construcción de una imagen autorial ${ }^{6}$ muy concreta: José Joaquín Benegasi y Luján es un poeta cuyo talento, junto a otras heredades, le ha sido legado por vía paterna ${ }^{7}$.

4. Con mayor o menor número de condicionantes internos y externos, siempre en el seno del "Campo literario" de su tiempo (BOURDieu, Pierre. Las reglas del arte: génesis y estructura del campo literario. Barcelona: Anagrama, 2006).

5. Acerca de este apellido, del que se ha subrayado en muchas ocasiones su procedencia italiana, uno de los descendientes de la familia, Rafael del Rosal Pauli, fallecido en 2012, afirma que se trata de una contracción y posterior evolución de "Venegas y Luján». Esta supuesta deformación, aunque no sabemos cuándo se produjo, también parece responder a esa necesidad bastante común de manipular la propia genealogía con el pretexto de conferirle un mayor auge, y, en cualquier caso, con un criterio similar al uso fraudulento por parte de Benegasi padre e hijo del cargo de la regiduría perpetua de la ciudad de Loja. Padilla Aguilera, Tania. "José Joaquín Benegasi y Luján (1707-1770): perfil vital». Cuadernos de Ilustración y Romanticismo: Revista del Grupo de Estudios del Siglo XVIII, 2019, n. ${ }^{\circ} 25$ (en prensa).

6. En este trabajo utilizaremos el concepto de «imagen autorial» siguiendo la noción de "selffashioning” aplicada al autor renacentista en GREENBLATT, Stephen. Reinassance self-fashioning: from more to Shakespeare. Chicago: University, 1984.

7. Acerca del concepto de firma en Benegasi, podemos suscribir las palabras de RuIz PÉREZ, Pedro. "Sentimental subjectivity and autorial subject: trajectory and three levels». En ÖzmEN, Emre y 
Vinculada a esta idea, juega un papel clave la edición que lleva a cabo José Joaquín de las obras de su padre en 1746, Obras líricas jocoserias que dejó escritas el señor don Francisco Benegasi y Luján', que su hijo acompañó muy hábilmente de algunos versos propios, de lo que se avisa ya en la propia portada?. En este sentido, queda clara la estrategia editorial de Benegasi, quien tres años antes da a la imprenta una obra firmada por primera vez con su nombre real ${ }^{10}$ : este publica ahora sus versos junto con los de su padre, aprovechándose claramente de la fama de su nombre, que ya es reconocible en el mercado de la época, pero convenientemente separados con el objeto de que el lector distinga la suya como una voz diferenciada. Podemos afirmar que esta obra marcará la posterior trayectoria literaria del autor, caracterizada por el cultivo de una poesía de arte menor en la línea de la que cultivó Francisco Benegasi, pero con un distintivo propio que encuentra su principal baza en los matices de una particular idea de lo jocoserio.

En este trabajo ${ }^{11}$, nos proponemos profundizar en la trayectoria literaria

\section{OBRAS LYRICAS J O C O-S E R I.AS, QUE DEXÓ. ESCRTTAS EL $S^{R}$. D. FRANEISCO BENEGASI $Y$ L U X A N," \\ CAVALLERO QUE FUE DEL ORDEN DE CALATRAVA, Governador, y Superintendente General de Alcazar de San Juan, Villanueva
de los Infantes, y Molina de Aragòn, del Confejo de fu Mageftad, en el de los Infantes, y Molina de Aragon, del Confejo de la Capilla, que en il Real Monalterio de San Geronymo de efta Corte fundó la fé́ora Doña Maria Anz de Luxán, \&ce. \\ VAX AñADIDAS ALGUN (AS POESIAS \\ de fu Hijo Don Jofeph Bencgafi y Luxàn, pofteriores á fu primer Tomo Lyrico, las que fe notan con efta Teñal *

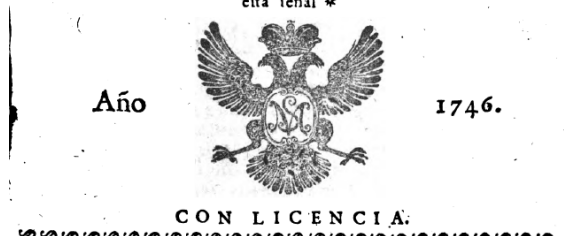

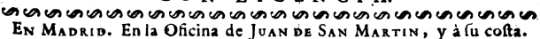

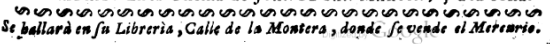

Portada de las Obras líricas jocoserias que dejó escritas el señor don Francisco Benegasi y Luján. Madrid: Oficina de Juan de San Martín, 1746.

Padilla Aguilera, Tania (coords.). El sujeto literario en la Monarquía Hispánica. Theory Now. Journal of Literature, Critique and Thought, 2019, n. ${ }^{\circ}$ 2.: "The rubric sanctions the identity, but also close it down, delimits it; the signature acts as a sign of identity, but it is not identity; the subject is recognized via his signature, but realizes himself during the writing experience that ends by putting his name in a text and unfolds in the path that leads to the printing press".

8. Título al que siguen, como luego hará el hijo con sus menos nutridos méritos, los cargos que este detentó: "caballero que fue del orden de Calatrava, gobernador y superintendente general de Alcázar de San Juan, Villanueva de los Infantes y Molina de Aragón, del consejo de su majestad, en el de Hacienda, regidor perpetuo de la muy noble ciudad de Loja, patrono de la capilla que en el real monasterio de san Jerónimo de esta corte fundó la señora doña María Ana de Luján, etc.».

9. "Van añadidas algunas poesías de su hijo, don José Benegasi y Luján, posteriores a su primer tomo lírico, las que se notan con esta señal*.

10. Nos referimos a sus Poesías líricas y jocoserias.

11. Que forma parte de mi tesis doctoral Imagen autorial y estrategias de mercado en José Joaquín Benegasi y Luján (1707-1770) y que se inserta en el Proyecto Coordinado «Sujeto e institución 
de Benegasi a través de la rúbrica de sus obras impresas ${ }^{12}$, que oscila entre los extremos del enmascaramiento y la exacerbación. El análisis de su firma bajo el presupuesto de una calculada y, por lo tanto, muy cuidada carrera editorial -lo que resulta plausible al hilo de algunos aspectos de la biografía del autor anteriormente analizados $-{ }^{13}$ nos permite abordar la trayectoria de Benegasi como la de un autor cuya coyuntura personal le hizo dar el paso desde el amateurismo a la profesionalidad. Para asegurarse la supervivencia en un campo literario cada vez más complejo, apostó por transformar los envites recibidos por sus colegas en exhibidas carencias personales que lo convirtieron en un autor simpático para el gran público, que esperaba de él una voz propia capaz de aunar lo clásico y lo popular, lo religioso y lo irreverente, lo personal y la máscara. Así pues, en el empeño de Benegasi por llegar a ser un autor profesional jugó un papel crucial su concepción del lector en un sentido moderno: si se convertía en un autor único e identificable en el mercado editorial, la fama conllevaría esa esperada retribución económica que tan valientemente renunció a percibir por otras vías.

\section{Desde el amateurismo a la BÚsQueda Del meCenazgo: PRimeros tanteos en EL CAMPO LITERARIO}

La primera obra impresa de Benegasi, titulada El no se opone de muchos y residencia de ingenios, se publicó en Madrid, donde residía el autor, en 1739, es decir, cuando este tenía 32 años. Aparece firmada bajo el seudónimo «Joaquín de Paz y Monroy».

Sabemos que su padre, Francisco Benegasi, celebraba regularmente una academia literaria en su casa a la que acudían algunos de los más célebres ingenios de la época, tal y como señala el marqués de la Olmeda en los preliminares ${ }^{14}$ de las citadas Obras líricas jocoserias...: «En la casa del autor había dos veces en la semana academia, donde concurrían las más conocidas habilidades de la corte, y sobre cada obra se discurría, corrigiendo en ellas las más leves imperfecciones».

literaria en la edad moderna» (FFI201454367-C2-1-R). En el seno de este proyecto estamos desarrollando varias bibliotecas digitales (paratextos, biografías, retratos y polémicas), cuyos textos están siendo analizados según el sistema de etiquetado informático TEI. Dada su enorme operatividad, en el análisis planteado en este artículo utilizo algunas de las categorías creadas para el establecimiento de concordancias entre los diferentes textos que integran las citadas bibliotecas.

12. Todas las referencias a la bibliografía de Benegasi han sido extraídas de RuIz PÉrEz, Pedro. "Para una bibliografía de José Joaquín Benegasi y Luján. Hacia su consideración crítica». Voz y Letra: Revista de Literatura, 2012, vol. 23, n. ${ }^{\circ}$ 1, pp. 147-169. No obstante, los títulos completos de los impresos mencionados en este trabajo, convenientemente adecuados a las normas ortotipográficas actuales, figuran en la bibliografía final.

13. Acerca de la compleja situación económica de Benegasi, principalmente tras la muerte de su padre, véase Padilla Aguilera, Tania. Op. cit.

14. En concreto, en la "Aprobación del señor don Ignacio de Loyola, marqués de la Olmeda $[\ldots]$, p. 2. ${ }^{\mathrm{a}}$. 
Podemos inferir que José Joaquín aprovechó los contactos paternos para abrirse paso en un panorama literario por el que pudo sentirse atraído desde una edad muy temprana.

Este supuesto contexto académico ofrece a nuestro autor el entorno adecuado para sus primeros tanteos literarios (círculo privado, soporte manuscrito) en relación con su concreto perfil vital (baja nobleza, hijo de literato). Sin embargo, era de esperar que no tardara en entregar alguna de sus obras a la imprenta, máxime teniendo próximo el antecedente de su padre, quien, al tiempo que había alcanzado cierta fama entre el gran público, principalmente por la publicación y representación de sus comedias, seguía obteniendo el reconocimiento de sus compañeros intelectuales y poetas, que constituían una tupida red de sociabilidad académica que contribuía a mantener esa condición de amateur que en cierto modo debería de resultar tranquilizadora en el seno de una familia como la de los Benegasi ${ }^{15}$. En esta primera etapa podemos aplicar a José Joaquín las afirmaciones que Jiménez Belmonte ${ }^{16}$ hace extensibles a la baja nobleza dieciochesca:

Lo significativo, sin embargo, no es tanto el aumento del número de nobles-poetas, que seguirá siendo bajísimo en comparación con el elevado número de nobles (con y sin título) en la España de entresiglos, sino más bien el hecho de que en el siglo XVIII (tanto en la primera como en la segunda mitad) la gran parte de obras impresas de poesía firmadas por nobles provenga de estos sectores más bajos de la nobleza, compuestos fundamentalmente por regidores, señores de vasallos y caballeros. La relación especular (admirativa y competitiva) de este sector de la nobleza con respecto a las prácticas culturales de la nobleza de sangre, pero también, quizás, el aprovechamiento del hueco que venía a dejar el progresivo alejamiento de esa nobleza de sangre de un panorama literario que ya no era el de antaño, podrían explicar ese posicionamiento de la nobleza media y baja en el campo literario dieciochesco.

Asimismo, tal y como hemos señalado antes, esta primera obra que Benegasi da a la imprenta aparece firmada bajo seudónimo ("Joaquín de Paz y Monroy»), lo que confirma más claramente ese apego al amateurismo propio de la específica condición de nuestro autor que, bien por razones de autocensura, bien por consejo paterno, opta por renunciar al soporte manuscrito y, como consecuencia, al destinatario privado, para apostar por una profesionalidad (soporte impreso, destinatario público) a la que se arroja con la protección de una máscara (seudónimo) que preserva su imagen de futuro regidor, de joven magistrado, al tiempo

15. Entre los autores que se mueven en un entorno exclusivamente académico, la publicación de la obra se percibe como un hecho que conlleva la pérdida de un determinado concepto de "estatus» que parece concernir tanto al ámbito ideológico como al socioeconómico. LefEvere, André. Traducción, reescritura y la manipulación del canon literario. Salamanca: Colegio de España, 1997, pp. 25 y ss.

16. JimÉnez Belmonte, Javier. Op. cit., p. 84. 
que sugiere su ADN (su nombre de pila y los apellidos más remotos de su estirpe). Incluso el formato elegido para la obra, en $8 .^{\circ}$, remite a unos códigos editoriales que nos retrotraen al siglo anterior y a una concepción muy concreta de la obra poética impresa (escasa elaboración, formato de faltriquera). En definitiva, todos estos mecanismos parecen responder a una actitud que se corresponde con los tanteos propios de un diletante que fantasea con encontrar un lugar propio y digno en la literatura que le permita poner su nombre y atributos al frente de sus creaciones. Así pues, es muy probable que nuestro autor, como demostrará a lo largo de sus textos posteriores, ya tuviera en la cabeza el ilustre ejemplo del afamado Lope de Vega.

Nuestra tesis de que el uso del seudónimo en El no se opone de muchos... se debe a su posición inaugural en la trayectoria de Benegasi más que a la naturaleza de su contenido queda probada por el hecho de que en la reedición de esta, que salió de las prensas ya en la década de los $60^{17}$, sí aparezca la firma del autor, a estas alturas perfectamente conocido por los lectores. Como veremos más adelante, el fenómeno de las reediciones jugará un papel importante en la trayectoria de Benegasi, pues constituirá un síntoma claro del éxito del que gozó, principalmente en su etapa de madurez.

En 1743, transcurridos cuatro años desde la publicación de su primera obra, Benegasi vuelve a dar a la imprenta otro texto, las mencionadas Poesías líricas $y$ jocoserias. Esta vez el texto se publica en el habitual formato en $4 .^{\circ}$ y aparece rubricado por el poeta, que acompaña su nombre del distintivo de su señorío y el ejercicio de su regiduría perpetua. Encontramos, por tanto, que nuestro autor, en un breve espacio de tiempo, ha pasado de ocultar su nombre bajo seudónimo a firmar con sus dos apellidos -incluyendo, por supuesto, el de su padre, que ya ocupaba un lugar bien definido en el campo literario de la época-, seguidos de sus credenciales. La explicación de este cambio debemos buscarla también en la

17. Existe una segunda impresión antes de esta, pero no se han encontrado referencias, así como otra reedición, post mortem, en 1789. En esta reimpresión la firma vuelve a enmascararse, esta vez con las siglas D. M. D. Q. B. En Aguilar PIÑAl, Francisco. Bibliografía de autores españoles del siglo XVIII, cit., se indica que esta edición es anunciada en el Correo de Madrid (27-VI-1789) como de don Miguel Quijano. En la Gaceta de Madrid (16/06/1789) su autor aparece identificado como don Miguel de Quijano Barreda, nombre que coincidiría con las siglas de la edición mencionada. No he encontrado ningún dato sobre este autor, lo que apunta a que pueda tratarse de una posible estrategia de venta del editor. Parece ser que en estas fechas la fama de Benegasi había ido disminuyendo. En la "reseña" literaria de esta obra que se incluye en el Memorial literario instructivo y curioso de la corte de Madrid (vol. 17, julio de 1789, pp. 389-393) no se identifica al autor; lo mismo que en el Diario de Madrid (jueves 17 de septiembre de 1789, p. 1040). En la Gaceta de Madrid, la obra se anuncia 4 veces (17/11/1739, 13/9/1740, 19/3/1743 y 2/6/1761) siempre con un único puesto de venta: la tienda de Francisco Romero, calle Mayor. Francisco Romero y Tejada era mercader, por lo que parece que esta no se llegó a vender en ninguna imprenta o librería. Queda pendiente la realización de un examen más exhaustivo de los anuncios de impresos de Benegasi aparecidos en la Gaceta de Madrid, que pueden aportar información de gran relevancia sobre el autor y el contexto de edición de sus obras. 
propia portada de la obra, en la que, tras el nombre y los cargos de Benegasi, se especifica que este «las dedica al excelentísimo señor marqués de Villena, duque de Escalona, conde de san Esteban de Gormaz, caballero del insigne orden del Toisón, etc.» ${ }^{18}$. En definitiva, en el momento en el que el poeta se propone, en una decisión perfectamente lógica en este momento de su trayectoria literaria, establecer una relación de mecenazgo ${ }^{19}$, es preciso que se presente ante el valedor económico escogido con sus apellidos y credenciales familiares y personales. Con esta publicación Benegasi ha cambiado su anterior rol de autor académico por un nuevo papel de autor criado, es decir, ha pasado de publicar bajo el paraguas del amateurismo a hacerlo bajo la protección del «escudo» de un mecenas.

Este paso dado por nuestro poeta lo sitúa temporalmente en un estadio intermedio en su camino hacia esa profesionalización que el autor parece desear. Solo esta idea puede explicar que, tras haber decidido llevar a imprenta una obra que a buen seguro era el resultado de una previa y abundante práctica manuscrita, tome ahora la decisión de publicar una segunda obra, esta vez firmada y convenientemente orientada hacia un mecenas. Si en el caso de la primera Benegasi parecía estar tanteando (de incógnito) el panorama literario madrileño de la época, en el caso de la segunda el poeta demuestra estar ya más convencido de lo que quiere y del lugar que desea ocupar en la república literaria, por eso activa el mecanismo más seguro y conocido para la profesionalización en el ámbito de las letras (aunque se trate de una profesionalización sui géneris, más vinculada a un sistema literario propio del siglo XVI que de la centuria anterior): la búsqueda de un protector que avale sus versos y, con ellos, su incipiente carrera literaria, necesitada a estas alturas tanto de un refrendo ideológico, como de su consecuente apoyo socioeconómico (estatus) ${ }^{20}$.

Las limitaciones de esta estrategia quedan evidenciadas con la vuelta del autor al seudónimo - $\mathrm{O}$ a alguna de sus variantes, como la anonimia o el acrónimoen sus publicaciones posteriores. Así, en la década de los 40 publica una serie de cinco obras cortas ${ }^{21}$ en formato $4 .^{\circ}$. Dos de ellas son epístolas: la Carta en prosa y en diferentes metros, que «escribíala a un pariente suyo Juan Antonio Azpitarte,

18. Se trata de Andrés Luis López-Pacheco y Osorio (1710-1746), grande de España que en 1738 fue nombrado tercer director perpetuo de la Real Academia Española. Evidentemente, Benegasi se busca al mejor de los mecenas posibles: vinculado tanto a la Corona, como a la recién creada institución académica.

19. Benegasi desempeña un papel bastante singular en la literatura de su tiempo, puesto que oscila entre las estrategias propias del mecenazgo clásico -que Lefevere denomina «indiferenciado»-, como es el caso del que hablamos, y el mecenazgo "diferenciado» que caracterizará a los escritores profesionales a partir de la segunda mitad del siglo, tal y como veremos en las obras posteriores de nuestro autor, en las que la clave del éxito reside en la aceptación de los lectores. Acerca de esta distinción, véase LEFEVERE, André. Op. cit., pp. 31-32.

20. Acerca de las particularidades biográficas que acompañan la carrera literaria de Benegasi, véase Padilla Aguilera, Tania. Op. cit.

21. Ninguna de ellas pasa de las 16 páginas, salvo la Vida de san Dámaso, que llega a las 90. 
y la da a luz quien, aunque no corre con el autor, anda con él»22, y la Carta en respuesta de otra, que le había escrito un amigo noticiándole cierto desengaño de una parienta ${ }^{23}$, que aparece sin firma. Las tres restantes son un atrevido "romance místico", Definición del mundo, de la hermosura, de la nobleza y del aplauso becha en un romance místico, que aparece firmada "por D. J. B. y L.»; un pronóstico, Pronóstico el más cierto y más breve que en estilo jocoso bace del nuevo cometa don Juan del Rosal en este romance, y la indecorosa Vida de san Dámaso ${ }^{24}$.

Como vemos, bien por los específicos subgéneros de estas obras, bien por el tono o el enfoque empleados en ellos, encontramos manifiestas razones que justifican el nuevo enmascaramiento del autor, que esta vez no da a la imprenta un compendio con sus mejores poesías, sino obras menores, que están social y/o literariamente estigmatizadas porque pertenecen al ámbito de la intimidad (las epístolas), al de la literatura de consumo (el pronóstico), o porque ofrecen un enfoque no ortodoxo sobre ciertos temas científicos o religiosos.

Aunque podríamos haber llegado a la misma conclusión en el caso de la primera obra publicada por el autor, El no se opone de muchos y residencia de ingenios, lo cierto es que la posición que estas obras ocupan en la trayectoria de Benegasi nos obliga a explicar el uso del seudónimo en ellas más como una clara estrategia de autocensura que como un ejercicio de tanteo del campo literario. A estas alturas de su trayectoria, nuestro poeta parece tener bien claro lo que quiere y cuál va a ser su estrategia a partir de ahora: una vez llevado a cabo su enmascarado debut impreso y tras haber ofrecido al mecenas de turno una muestra de lo que es capaz de hacer, se contenta con divertirse bajo la máscara hasta que llegue el momento de poder firmar con orgullo hasta las producciones más indecorosas. Esto último únicamente será posible cuando alcance un peculiar tipo de fama estrechamente ligada al incipiente mercado editorial de la época ${ }^{25}$.

22. Aguilar Piñal señala a Benegasi como editor. En la Fama póstuma el autor reclama la obra como propia y explica el seudónimo. El texto se fecha a 28 de enero de 1744. Aguilar PiÑal, Francisco. Bibliografía de autores españoles del siglo XVIII, cit.

23. Palau se la atribuye a Benegasi (27322). Palau y Dulcet, Antonio. Manual del librero bispano-americano; bibliografía general española e hispano-americana desde la invención de la imprenta hasta nuestros tiempos, con el valor comercial de los impresos descritos, tomo xiv. Barcelona: Librería anticuaria de A. Palau, 1962. Según Aguilar Piñal (4075) data de 1747. Aguilar Piñal, Francisco. Bibliografía de autores españoles del siglo XVIII, cit.

24. Esta obra no aparecerá firmada por el autor hasta su reedición de 1763, cuando Benegasi ya era sacerdote, lo cual no deja de resultar significativo, como plantearemos más adelante.

25. Esta idea estaría vinculada con el concepto de "mecenazgo diferenciado» de LEFEVERE, André. Op. cit. A este respecto, véase la nota 15. 


\section{LA CATAPULTA PATERNA Y LO JOCOSERIO: HERENCIA Y FAMA}

De toda la producción literaria de Benegasi salida de las prensas entre mediados de los años 40 y mediados de los 50, la única obra que encontramos sin firmar es una "comedia burlesca». En un principio, en este caso podría interpretarse la anonimia como un deseo por parte del autor de no identificarse con un texto dramático que supondría una excepción genérica en su carrera literaria. Además, el carácter burlesco de este puede resultar más problemático en la construcción de una imagen autorial más o menos seria. Sin embargo, el título de esta obra evidencia que el enigma de la firma forma parte de un juego de equívocos extendido a todos los ámbitos de la edición (género, título, autor e impresor):

Comedia (que no lo es) burlesca, intitulada "Llámenla como quisieren", su autor ella lo dirá. Y se hallará donde la encuentren, y será en la imprenta y librería de Juan de San Martín, calle del Carmen, donde se hallarán otros papeles curiosos escritos por el mismo autor.

La referencia a "otros papeles curiosos escritos por el mismo autor», además de ponernos en la pista de una identidad concreta, constata la existencia de una trayectoria, presumiblemente exitosa, por parte del velado autor. La segunda edición de la obra, que data de 1761, es mucho más explícita, y en la portada tras las palabras "su autor, ella lo dirá», se añade: "y por si lo calla, don José Joaquín Benegasi y Luján, etc.», con lo que el editor parece no querer desaprovechar el filón de ventas de un poeta a estas alturas de sobra conocido por el gran público. Además, la inclusión en esta edición del sainete El amor casamentero hace que esta obra deje de constituir una isla en la producción dramática de Benegasi, lo que también invita a la explicitación de su nombre en la portada, aunque solo sea con el propósito de establecer algún vínculo que permita hablar de una sucinta trayectoria impresa en el género dramático que, por otra parte, a nuestro autor no le era en absoluto ajeno.

En lo que respecta a la producción firmada de Benegasi durante la mencionada década, tienen un papel fundamental las citadas Obras líricas jocoserias que dejó escritas el señor don Francisco Benegasi y Luján, entre las que José Joaquín incluye algunas composiciones propias. Francisco Benegasi había muerto en 1743, con lo que esta obra, publicada tan solo tres años más tarde, cumple para el hijo, además de la función del homenaje pretendido, una inigualable oportunidad de autopromoción. Esta brillante estrategia editorial volverá a repetirla Benegasi años más tarde con la publicación de la Fama póstuma (1754) en homenaje a su fallecido amigo el poeta fray Juan de la Concepción, tal y como veremos después.

A través de la compilación de los versos de Francisco Benegasi, José Joaquín orquesta un pensado homenaje póstumo que evidencia exclusivamente la faceta lírica de este autor, que no debemos olvidar que era principalmente conocido por su producción dramática, sobre todo por sus comedias y sainetes. Parece claro que Benegasi selecciona y ordena los versos de su padre con una evidente 
intención editorial: el desarrollo de una velada estrategia de autopromoción que persigue la definitiva conquista de su firma autorial.

En relación con esta propuesta del autor-editor -en este caso deberíamos considerar a José Joaquín Benegasi más bien como un editor, aunque algo oportunista-, debemos señalar dos aspectos fundamentales. Por una parte, Benegasi lleva a cabo un movimiento de recuperación de la firma de su padre para presentar al lector-comprador (en este caso su estrategia es claramente mercantilista) una obra cerrada, que reactiva unas formas poéticas muy concretas (barroquismo, arte menor, temas populares) y que se encuadra en el periodo post mortem en la trayectoria de este autor, de sobra conocido por el público de la época. Esta última circunstancia hace que tenga que leerse bajo el obligado membrete de homenaje póstumo, lo que invita a una lectura no ya solo desde la aceptación, sino desde la celebración. Sin embargo, por otra parte y de forma simultánea, José Joaquín Benegasi, al añadir las obras propias al homenaje a su padre, distinguiéndolas claramente, lleva a cabo un ejercicio de suplantación nominal que se ve reforzado tanto por la utilización del singular apellido "a la italiana», como por la similitud estético-formal de la propuesta poética de sus propios versos, que parecen situarse tras la estela literaria del padre.

Así pues, Benegasi aprovecha el benevolente contexto en el que resulta plausible la edición de los versos de su padre para incluir una muestra de su propia producción poética. Con esta decisión, nuestro autor logra soslayar al fin las dificultades que se le presentan al inicio de la carrera literaria ${ }^{26}$, utilizando la posición privilegiada de su padre, que se encuentra justo en el punto opuesto, esto es, al final de la misma. En este sentido, con una suerte de traslación nominal, el hijo aprovecha el estatus del padre para hacerlo propio por la vía del apellido. En definitiva, la muerte de su padre confiere a José Joaquín Benegasi, además del testigo de la herencia ${ }^{27}$, con el consiguiente "monopolio" del apellido en el ámbito de las letras españolas, la libertad necesaria para tomar sus propias decisiones en lo que concierne a la publicación de su obra y al uso de su firma, es decir, a todo lo que atañe a la conquista de un nombre propio, reconocible por los lectores-compradores, en el campo literario madrileño de la época.

Esta edición conjunta resulta, además, particularmente relevante en la medida en que, a partir de su publicación, se observa una variación en lo que respecta a la firma de Benegasi en relación con el contenido de las obras impresas. Durante la década de los 50 y hasta el fallecimiento del autor, incluso hasta varios años

26. Principalmente a la hora de abrirse paso en un campo literario en el que las posiciones suelen ocuparse tras un periodo inicial de hostilidad al que luego siguen una serie de tensiones que se derivan de la propia posición ocupada. Bourdieu, Pierre. Op. cit.

27. Esto constituye una importante baza en una sociedad en la que los privilegios de clase siguen encontrando su fundamento en la sangre. 
después de su muerte, encontramos que este exhibe su nombre y apellidos seguidos de sus credenciales, salvo en contadas excepciones.

En 1750 Benegasi publica convenientemente firmada la Vida del portentoso negro san Benito de Palermo, una obra que se encuentra en la órbita estético-conceptual de la Vida de san Dámaso, que, como vimos, se publicó sin firma. Las continuas reediciones de aquella, que volvió a pasar por las prensas en 1752, en 1763 y en 1779, nueve años después de la muerte del autor, prueban claramente el éxito que tuvo. En la portada de la primera edición aparece únicamente el nombre completo del autor, sin las credenciales que ya había exhibido en la edición de sus Poesías líricas y jocoserias. Podemos interpretar esta ausencia como un discreto intento de velar la propia identidad: en el caso de una obra religiosa como lo es la presente, quizá no resulte demasiado conveniente exhibir unos humildes cargos nobiliarios.

Esta tesis queda fortalecida por las reediciones de 1763 y 1779, en las que figura tras el nombre del autor su reciente ordenación religiosa: "por fray don José Joaquín Benegasi y Luján, canónigo reglar de nuestro gran padre san Agustín, del hábito de san Antonio Abad». En el caso de estas dos reediciones, parece incluso que es este ordenamiento el que justifica la nueva reimpresión de la obra, cuyo carácter religioso queda así respaldado. En relación con este aspecto, es tal vez su característico tono jocoserio, unido al hecho de que está escrita en arte menor, lo que la aleja del decoro habitual en este tipo de obras. Esto quizá era percibido como un inconveniente por el autor y fue lo que pudo llevarlo a firmar la primera edición exclusivamente con su nombre, con lo que, pese a dar un paso más con respecto a su anterior vida de santo, aún manifestaba una actitud cautelosa al respecto. Sin embargo, la ordenación sacerdotal en la etapa final de su vida, unida al hecho de contar ya con una trayectoria literaria bien definida y reconocida por los lectores, contribuye a conferir a la obra una supuesta seriedad de la que el autor parecía considerar que estaba necesitada.

En la misma línea, también se publica en 1752 una edición de las "poesías líricas» de Benegasi en la que se subraya en la portada que contiene la Vida de san Dámaso, muy probablemente para aprovechar el filón de ventas de la 2. ${ }^{\text {a }}$ edición de la Vida de san Benito de Palermo, con la que coincide ese año en las prensas. El revelador título que aparece en la portada es el siguiente:

Poesías líricas y, entre estas, la Vida del glorioso san Dámaso, pontífice máximo, natural de Madrid, martillo de la herejía, diamante de la fe, crisol de la castidad y especialísimo abogado de los perseguidos con falsos testimonios, escrita en redondillas jocoserias. Su autor, don José Joaquín Benegasi y Luján, señor de los Terreros y Valdeloshielos, regidor perpetuo de la ciudad de Loja y patrono de la capilla que en el real monasterio de san Jerónimo de esta corte fundó la señora doña Mariana de Luján, etc. Tomo IV²8.

28. Palau (27317), sobre la condición de tomo IV de la obra del autor señala: «Probablemente será una distracción de los censores, pues no se tiene noticia de que las producciones de Benegasi se hayan publicado coleccionadas", lo que contrasta con las frecuentes referencias de las portadas. PALAU 
Como vemos, en esta edición el poeta sí incorpora sus propias credenciales, ya que la composición poética religiosa resaltada forma parte de un corpus global. Además, la referencia al «tomo IV» indica la existencia de un criterio compilador que convierte en necesaria esta mención. Por otra parte, esta edición del poema incorpora una referencia religiosa previa al ordenamiento sacerdotal del autor que desempeña un papel similar al que encontramos en las ediciones exentas posteriores. En ambos casos el empeño del autor y/o del editor parece orientarse hacia la manifestación de la faceta religiosa de Benegasi. Esta contribuiría a soslayar el tono y las decisiones formales, a priori indecorosas para una vida de santo, adoptados por este.

De esta forma, la conquista por parte de Benegasi de su propia voz siempre se produce en términos relativos, de lo que es sintomático que el autor haga continuas referencias, principalmente en los paratextos de sus obras, a su natural inclinación al arte menor y a lo jocoso, con una actitud con la que parece querer justificarse. Así lo vemos en este fragmento de un romance ${ }^{29}$ :

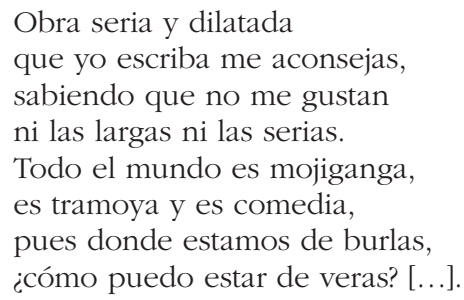

En cualquier caso, la inseguridad de Benegasi ante su propia propuesta poética evidencia su celo en la actividad literaria, lo que nos lleva a descartar la aleatoriedad de cualquier cambio en la firma y los atributos que aparecen en las portadas de sus impresos, así como en las referencias concretas que figuran en el interior de sus obras o en los paratextos, habitualmente metaliterarios, que las anteceden. Esta actitud de justificación ante la propia obra, a menudo acompañada de cierta autocrítica burlesca, se convertirá en una marca autorial muy característica en lo que podría denominarse «etapa de madurez» de Benegasi.

\footnotetext{
y Dulcet, Antonio. Op. cit. Cito a través de Ruiz Pérez, Pedro. "Para una bibliografía de José Joaquín Benegasi y Luján. Hacia su consideración crítica», cit., pp. 157-158.

29. Incluido en Poesías líricas y jocoserias, pp. 49-51. En el índice se titula "Excusándose de escribir en serio", pero en el rótulo que lo antecede reza: "Cuando salió cierto libro místico le aconsejó un sujeto escribiese alguna obra seria y dilatada, cuyo asunto fuese reprehender varias costumbres no buenas, y el autor se excusa por los motivos que da».
} 


\section{Benegasi ANTE El ESPEJO: El CiClO DE SENECTUTE}

Más allá del hecho de que la etiqueta de senectute ${ }^{30}$ aluda a la trayectoria literaria en relación con la edad del autor, aplicamos a Benegasi este marbete para englobar un período de su actividad poética particularmente caracterizado por la convivencia de una sinceridad testimonial -las obras producidas en esta etapa tienen una fuerte impronta personal, al tiempo que están ligadas a acontecimientos circunstanciales que nuestro autor vive y narra, y acerca de los cuales reflexiona en primera persona-, junto a la presencia de una serie de estrategias editoriales que encuadran definitivamente su producción literaria en el marco de la profesionalidad autorial. Ambas características, que a priori parecen incompatibles, coexisten en las obras de esta etapa, en la que Benegasi acaba conquistando al fin su particular espacio en el seno del campo literario madrileño de la época.

Desde la década de los 50 hasta la muerte del autor, e incluso en las reediciones de sus obras realizadas tras su fallecimiento, toda la producción de Benegasi aparece firmada con su nombre y apellidos, seguidos, en la mayor parte de los casos, de sus habituales credenciales. Como ya señalamos al principio, no podemos descartar la influencia de la entrada en vigor de las nuevas leyes de responsabilidad legal decretadas por Carlos III, que obligaban a firmar los textos que se publicaban con el objetivo de tener un mayor control sobre estos. Estamos ante las primeras medidas legales que surgen tras las iniciales muestras de una clara conciencia autorial, que derivarán a lo largo de la siguiente centuria en algo parecido al actual concepto del copyright ${ }^{31}$. Sin embargo, en esta etapa Benegasi sigue una estrategia editorial muy clara en la que el uso del seudónimo no parece tener cabida.

Entre los 40 y los 60 años -Benegasi murió a los 63-, nuestro autor incrementará la publicación de textos de carácter circunstancial, lo que es sintomático de un mayor grado de profesionalización en el campo literario. Mediante estas publicaciones el poeta se exhibe como un autor alejado tanto del ámbito académico, en el que predomina la poesía lúdica, gratuita, como del culto a la inspiración y al genio natural que acompañan al vate iluminado, tradicionalmente asociado al retiro campestre, que desde el siglo XVI se convertirá en una referencia para los nobles eruditos ${ }^{32}$.

30. Considero particularmente útil la utilización de este concepto en el mismo sentido en el que se aplica al perfil de Lope de Vega, autor al que Benegasi sin duda tiene muy presente en esta etapa de su vida, en Rozas, Juan Manuel. "El ciclo de senectute». Estudios sobre Lope de Vega. Madrid: Cátedra, 1990, pp. 73-133.

31. A este respecto, véase FOuCAult, Michel. "¿Qué es un autor?». Boletín de la Sociedad Francesa de Filosofía, 1969, año 63, n. ${ }^{\circ} 3$, julio-setiembre.

32. A este respecto, véase STROSETZKI, Christoph. La literatura como profesión (En torno a la autoconcepción de la existencia erudita y literaria en el Siglo de Oro español). Kassel: Reichenberger, 1997, pp. 60-64; y Padilla Agullera, Tania. Op. cit. 
Durante esta etapa de transición entre madurez y ancianidad, Benegasi publicará bajo su nombre obras que dejan constancia de sucesos históricos extraordinarios, bien para celebrarlos, como el soneto que dedica a la firma del concordato con la corte romana ${ }^{33}$, bien para lamentarse por ellos, como es el caso del terremoto de 1755 , al que el autor consagra dos textos ${ }^{34}$. Asimismo, en esta etapa son numerosas las obras dedicadas a nobles o en la que estos desempeñan un papel relevante a raíz de un acontecimiento histórico-vital que los compete de alguna manera o de los que son directamente protagonistas. Este es el caso de las composiciones dedicadas Fernando VI $^{35}$, Carlos III $^{36}$, María Amalia de Sajonia ${ }^{37}$, Isabel de Farnesio ${ }^{38}$, el conde de Valparaíso ${ }^{39}$ o el duque de Alburquerque ${ }^{40}$, entre otros.

En todos estos textos Benegasi manifiesta una actitud próxima a la del poetacriado en la que activa todos los mecanismos propios del autor en busca de mecenazgo (circunstancialidad, servilismo, alabanza). Sin embargo, en nuestro autor este comportamiento se convierte en paródico, sobre todo a causa del indiscutible "sello propio" de sus textos, que son singularizados principalmente a través de tres mecanismos de los que Benegasi parece perfectamente consciente: 1. El habitual enfoque jocoserio con el que a menudo enmascara una sátira de costumbres; 2 . La preponderancia del arte menor, y 3. Una presencia continua del yo autorial, que aporta una ingente información autobiográfica e ideológica que resulta de gran ayuda para reformular ese prejuicio que surge en un primer encuentro con los textos. En cualquier caso, parece claro el vínculo existente entre la actitud crítica de Benegasi en sus textos y su compleja situación vital, sobre todo en esta etapa de su vida, que acaba con una ordenación sacerdotal en la que la falta de fondos económicos juega un papel determinante ${ }^{41}$. Sin embargo, a pesar de que «las circunstancias de su vida le condujeron a esa crítica, a veces mordaz, su poesía no fue solemne ni grave ni seria sino eminentemente crítica y burlesca ${ }^{42}$.

33. El citado concordato tuvo lugar en 1753.

34. Descripción del terremoto según se experimentó en la villa de Herencia... (1755); y Con el motivo del terrible temblor de tierra sucedido en el día de Todos los Santos... (1755).

35. Rasgo métrico... (1759?).

36. Papel en prosa y diferentes metros celebrando los sobresalientes talentos... (1755).

37. Romance beroico y glosa de una quintilla... (1760).

38. Respetuosa súplica que a la reina madre... En relación con este texto, véase LóPEz ALEMANY. "Un poeta en deuda: José Benegasi y Luján y el mecenazgo de Isabel de Farnesio». Dieciocho, 2019, 5 (Anejos), Fall, pp. 163-177.

39. Al señor don Juan Francisco Gaona y Portocarrero, conde de Valparaíso... (1754?).

40. Con el motivo de haber pasado a mejor vida... (1757?). Esta obra se vio envuelta en una polémica inquisitorial cuya documentación se conserva en el Archivo Histórico Nacional. Actualmente estoy preparando un artículo al respecto.

41. Padilla Aguilera, Tania. Op. cit.

42. Ferreira Prado, María Cecilia y Servera Baño, José. "José Joaquín Benegasi: de la poética popular y la poesía barroca a la autobiografía de un "novator"». Dieciocho, 2018, 41.1, Spring, pp. $107-130 ; 115$. 
En esta etapa firma el autor una obra, su Panegírico de muchos, envidiados de no pocos, en la que ratifica la originalidad de su apuesta literaria combinando los tradicionales elementos del mecenazgo con el planteamiento de una voz propia caracterizada por la ironía, la ambigüedad de lo jocoserio y la autoparodia. Precisamente en busca de estos elementos que evidencian la moderna actitud que Benegasi adopta en el anquilosado panorama literario de su tiempo, profundizaremos en tres obras que considero particularmente representativas de esta etapa: la Fama póstuma (1754), que dedica a la muerte de su amigo fray Juan de la Concepción; la Descripción festiva (1760) de los actos programados con motivo de la llegada al trono de Carlos III y doña María Amalia, y el papel osadamente titulado Benegasi contra Benegasi (1760), con el que el autor se defiende de las críticas que dice haber recibido tras la publicación de la obra anterior.

La Fama póstuma del reverendísimo padre fray Juan de la Concepción $n^{43}$ es presentada por Benegasi como un homenaje a su amigo, fallecido el año anterior. La idea que parece articular la obra es la habitual en estos casos: rendir tributo al poeta difunto mediante la publicación de una de sus obras señaladas, en este caso se trata de la titulada Escuela de Urania ${ }^{44}$. Esta va acompañada de una serie de paratextos en los que otros escritores coetáneos, entre los que se encuentran amigos y compañeros del fallecido, son convocados por el promotor del homenaje, en este caso, Benegasi, para dedicar una serie de composiciones al poeta difunto.

Así pues, con su propuesta, Benegasi logra concitar a una serie de autores que, como cabe suponer, evidencian la red de sociabilidad de fray Juan de la Concepción. José Villarroel, Francisco Monsagrati ${ }^{45}$, Francisco Scoti o el propio Diego de Torres Villarroel son algunos de los autores cuyas composiciones abren el homenaje al por entonces célebre y carismático fray Juan de la Concepción (1702-1753), a quien unió una amistad fuerte y duradera con nuestro autor. Como no podría ser de otra manera, Benegasi incluye entre los poemas dedicados al genio fallecido bastantes composiciones propias, con lo que él queda perfectamente encuadrado en la república literaria propuesta.

De esta forma, los preliminares de la Fama póstuma -que de una forma intencionada acaban constituyendo la parte fundamental de la obra-conforman una suerte de selecta república literaria en la que el autor se inserta cómodamente, logrando así un autoencuadre a su medida en lo que pudiéramos denominar un canon horizontal. De este modo, al tiempo que Benegasi logra evidenciar su singularidad con respecto a otros autores contemporáneos, entre los que se establecen los consabidos vínculos profesionales de admiración y/o competencia,

43. En el marco de mi tesis doctoral, actualmente estoy trabajando en una edición modernizada y ampliamente comentada de este texto.

44. Fama póstuma, pp. 23-53.

45. La Fama póstuma está dedicada a Raimunda María Francisca de Biempica y Sotomayor y Ruiz de Llanos, esposa de Antonio Monsagrati, probablemente de la familia del poeta. 
consigue activar las necesarias nociones de generación o grupo, lo que parece una condición indispensable en el camino hacia la fama. Prueba claramente esta inferencia inicial el hecho de que nuestro autor cierre la obra del homenajeado con una nota ${ }^{46}$ en la que incluye las obras "que hasta hoy tengo dadas a la luz", tras excusarse alegando que lo hace con el objetivo de evitar confusiones, es decir, para evitar que le atribuyan las que no son suyas o que les atribuyan a otros las que sí lo son. Con esta actitud, Benegasi demuestra haber conquistado al fin su propio nombre y, con él, una fuerte conciencia autorial que rehúye el anonimato, el seudónimo o las falsas atribuciones. Esto es posible en el momento en que puede hablarse de la existencia de una extensa trayectoria con un indiscutible sello personal.

Esta lista de sus obras, que está precedida del «Índice de las obras del reverendísimo padre fray Juan de la Concepción", impresas y manuscritas ${ }^{47}$, pone en estrecha relación al editor y al autor del texto, de suerte que Benegasi parece tenerse a sí mismo como coautor de la obra que dedica a su amigo. En este sentido, la Fama póstuma le brinda la posibilidad de concitar a una nutrida parte del campo literario de la época para rendir tributo a un amigo, haciendo, además, de editor de una de sus obras. Al mismo tiempo, logra promocionar su imagen autorial a través de la exhibición de su red de relaciones -entre las que puede contarse al celebérrimo Torres Villarroel-, de una muestra de sus versos y, finalmente, del listado "oficial» de sus producciones.

No podemos dejar de señalar la relación existente entre esta obra y la conocida Fama póstuma a la vida y muerte del doctor fray Lope de Vega Carpio realizada por Juan Pérez de Montalbán en 1636, que, al igual que en el caso de la dedicada a fray Juan de la Concepción, se publica al año de la muerte del homenajeado. Como ya hemos constatado en este y otros trabajos sobre Benegasi, el ejemplo vital y literario del Fénix acompañó a nuestro poeta a lo largo de toda su vida, convirtiéndose en un verdadero modelo de conducta que juzgamos determinante en alguna de las decisiones que Benegasi toma a lo largo de su vida. En este caso, el autor convierte a su amigo y compañero difunto en un nuevo Lope. Sin embargo, él, en el papel de un obligado Pérez de Montalbán, parece resistirse a situarse en el discreto segundo plano que le correspondería, pugnando disimuladamente por compartir con fray Juan de la Concepción -quien, por cierto, al igual que Lope, también era conocido por el sobrenombre de «el Monstruo»- el lugar del gran dramaturgo del XVII.

Esta asociación, que debía de estar presente en la mente de la mayor parte de los lectores de la época, logra activar no solo la idea de república literaria antes señalada, sino también el más ambicioso concepto de parnaso. Así, al mismo tiempo que la nómina autorial que participa en el homenaje al poeta difunto

46. Fama póstuma, pp. 65-67.

47. Fama póstuma, pp. 65-67. 
-entre la que Benegasi adopta un papel protagonista- activa un eje horizontal de relaciones, las manifiestas conexiones estético-formales con una Fama póstuma anteriormente elaborada en similares condiciones logran activar un eje vertical que coloca a fray Juan de la Concepción, y con él al omnipresente Benegasi, al mismo nivel que los clásicos -en este caso, a la altura de su admirado Lope-.

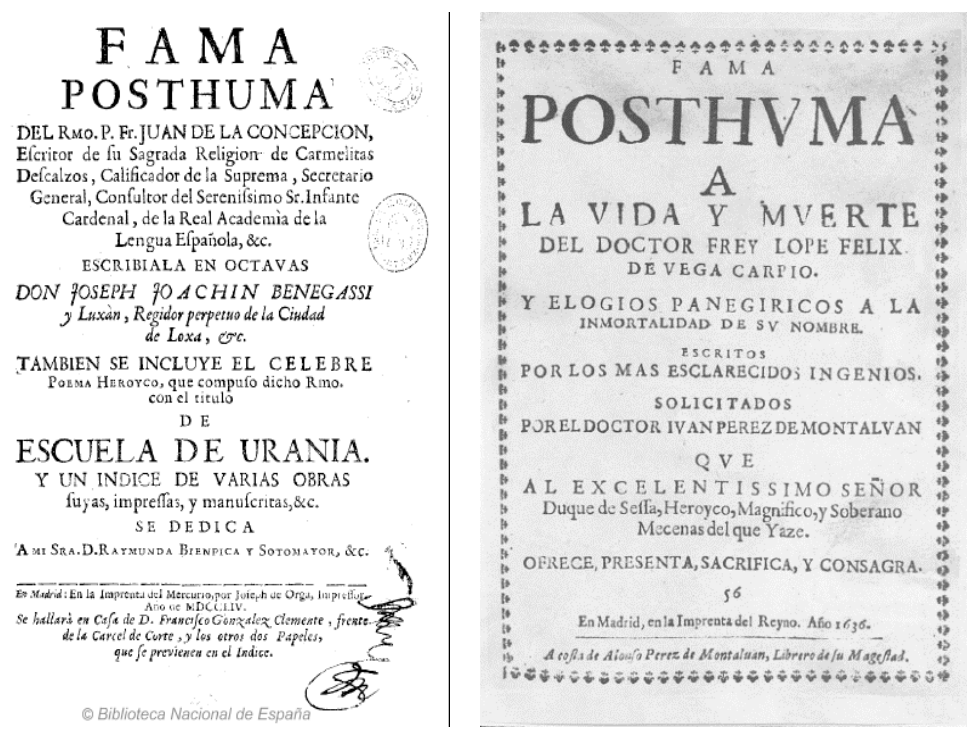

Portadas de la edición de la Fama póstuma del reverendísimo padre fray Juan de la Concepción, fechada en 1754 (izquierda) y de la Fama póstuma a la vida y muerte del doctor fray Lope de Vega Carpio, publicada en 1636 (derecha).

En definitiva, podemos interpretar la Fama póstuma como un sincero tributo a un amigo y compañero que, sin dejar de desempeñar la desinteresada función con la que fue concebida, Benegasi logra transformar en una obra fundamental en su estrategia de mercado. Con la publicación de este texto Benegasi le saca partido al prestigio de su amistad con el homenajeado, al tiempo que exhibe sus contactos en el campo literario (podemos presuponer que algunos de ellos incluso se produjeron a raíz de la publicación de la propia obra). Esto le confiere un lugar en la república literaria de la época mediante la repetición de una estrategia histórica reconocida que recupera el nombre de Lope de Vega, que sigue siendo un referente estético para todos los autores concitados en el homenaje, en la medida en que todos ellos participan de una estética claramente postbarroca. La activación de los ejes vertical (parnaso) y horizontal (república literaria), sincrónico y diacrónico, permite encuadrar esta obra en unas coordenadas sumamente favorables de las que, en última instancia, es Benegasi quien se beneficia, entre 
otras razones porque, a diferencia de fray Juan de la Concepción, el concepto de fama en su caso no es en absoluto póstumo, sino muy real e inmediato ${ }^{48}$.

Unos años más tarde, saldrá a la imprenta bajo la firma de nuestro Benegasi la Descripción festiva ${ }^{49}$ de las fiestas celebradas en Madrid para conmemorar la llegada al trono de los nuevos monarcas, que había tenido lugar el año anterior. Los testimonios de prensa de la época, recogidos en la Gaceta de Madrid y el Mercurio bistórico, nos proporcionan datos detallados sobre la forma en que se engalanó Madrid para la ocasión -arcos de triunfo, esculturas, guirnaldas-, el itinerario seguido por los monarcas, los actos religiosos que tuvieron lugar en los diferentes templos, las representaciones teatrales en el Retiro y las corridas de toros en la plaza Mayor. Además, contamos con algunos testimonios más subjetivos del evento, como el firmado por el periodista Nifo; incluso existe una "documentación gráfica» de la celebración: los óleos realizados por el pintor Lorenzo de Quirós. Como vemos, en este caso Benegasi apuesta por abordar un evento social de cierta relevancia que suscitó un gran interés testimonial en la época. No obstante, la propuesta de nuestro autor resulta absolutamente novedosa.

A continuación de unos paratextos metaliterarios de enorme importancia para la comprensión del texto, como veremos luego, el autor, siguiendo la conocida premisa ut pictura poiesis, desarrolla una pormenorizada descripción de la carrera festiva, esto es, del itinerario del desfile, pero también de las representaciones teatrales y de las corridas de toros que tienen lugar, de las que da cuenta prolijamente. Los recursos empleados por Benegasi -formas en presente y gerundio, continuas interpelaciones al lector, como si fuera un interlocutor que, en efecto, también está presente en las fiestas- confieren al texto la viveza del testimonio en primera persona, como si el propio autor los hubiera vivido personalmente. Sin embargo, si cotejamos el itinerario propuesto por Benegasi y las descripciones recogidas en la prensa de la época, observamos que nuestro autor sigue al pie de la letra estos textos, en los que debió de basarse a la hora de realizar su propuesta.

Esta misma idea, que podríamos calificar de "fingimiento testimonial», es extrapolable a otros aspectos de la obra. En primer lugar, parece que nos encontramos de nuevo, como planteábamos más arriba, ante un texto circunstancial salido de la pluma de un autor-criado que se mueve en los tradicionales círculos del mecenazgo (literatura por encargo o literatura nacida bajo el amparo o para buscar la protección de un noble, en este caso, los propios monarcas).

48. Acerca de la estrategia de Benegasi en su particular homenaje a fray Juan de la Concepción y sobre el concepto de fama en la mentalidad dieciochesca, véase RuIz PÉREZ, Pedro. «El sujeto autorial dieciochesco: a partir de una Fama póstuma». En LoREnzo Álvarez, Elena de (coord.). Ser autor en la España del siglo XVIII. Gijón: Ediciones Trea, 2017, pp. 479-508.

49. En el marco de mi tesis doctoral, he preparado una edición modernizada y ampliamente comentada de este texto. 


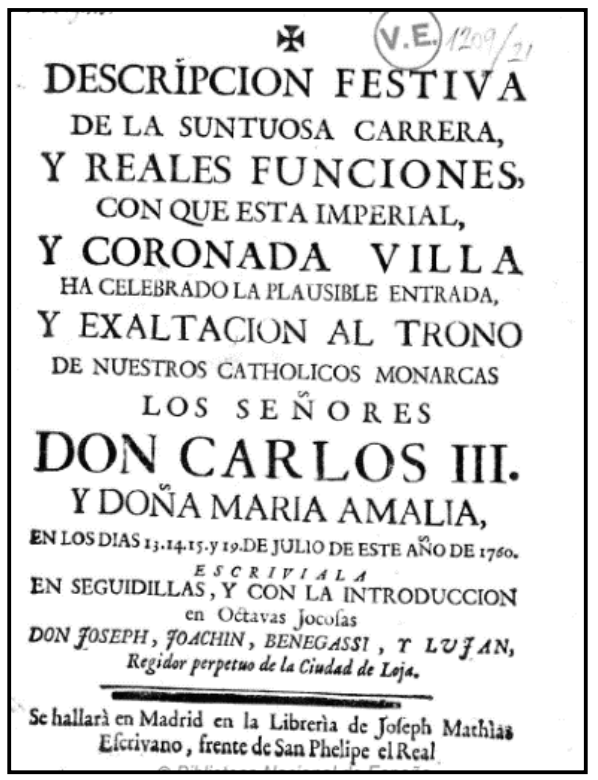

Portada de la Descripción festiva de la suntuosa carrera y reales funciones. Madrid, 1760.

Como vemos, ya desde la portada de la obra parece orientarse la lectura en esta dirección, al destacar con una tipografía de mayor tamaño el evento señalado, así como los protagonistas del mismo, tanto la circunstancia ("exaltación al trono») como los personajes ("don Carlos III" y, en una tipografía algo menor, "doña María Amalia»). Sin embargo, en una tipografía de muy reducido tamaño en relación con los elementos destacados, encontramos algunas de las claves que van a poner en tela de juicio la información anterior: se trata de una obra escrita «en seguidillas y con la introducción en octavas jocosas", lo cual, ni tan siquiera a estas alturas de siglo, resulta demasiado decoroso en una descripción testimonial de estas características, firmada, además, por «don José Joaquín Benegasi y Luján», cuya trayectoria es ya sobradamente conocida, tal y como prueba la indicación final del lugar en el que puede adquirirse el libro ("Se hallará en Madrid en la librería de José Matías Escribano, frente de San Felipe el Real»).

A pesar de que ya hemos visto muestras de oscilación entre los mecanismos del mecenazgo y la profesionalidad a lo largo de la producción de Benegasi, es en esta etapa que hemos denominado de senectute en la que encontramos una estrategia más perfilada. En la Descripción festiva el autor recurre a los cauces habituales en el siglo anterior (literatura circunstancial, fechada a partir del evento en cuestión, 
dedicada a un noble) $)^{50}$ para ofrecer una propuesta muy personal: en el prólogo se dirige a los lectores que compran sus libros, a quienes atribuye todo el poder de aceptación o rechazo de su actividad literaria; apuesta por el cauce métrico de las seguidillas compuestas para describir unos acontecimientos cuyos protagonistas exigirían una mayor observancia del decoro y adopta una actitud muy crítica con los nobles a los que alude a lo largo de la carrera -principalmente a través de las fachadas de sus casas, adornadas para la ocasión-, así como con los habitantes de Madrid, que presumiblemente son el público al que va dirigida la obra.

El propio autor, receloso ante la recepción de su atrevida propuesta, decide llevar su inquietud a los preliminares de la obra. De esta forma, aleja la dedicatoria al mencionado marqués de Estepa de la tradición del mecenazgo para encuadrarla en el nuevo paradigma del mercado editorial: Benegasi le demanda al noble una labor de protección que cifra en la ingeniosa dilogía "escudo", con la que al mismo tiempo alude a la habitual necesidad económica del artista, algo que tampoco parece demasiado decoroso en una dedicatoria de estas características. Por lo que puede inferirse de sus palabras, Benegasi apela al noble como aval cualificado ante las posibles críticas que pueda recibir por parte de los lectores/compradores, a quienes, pese a sus reticencias, el autor concede la última palabra. Así, en los versos que dedica al noble, afirma:
Escudo en ti ha de tener este pobre rasgo rudo; favor que de ti no dudo, por quien eres, por tu genio $\mathrm{y}$ en fin para que un ingenio diga que tiene un escudo ${ }^{51}$.

En cualquier caso, lo que más parece preocupar a Benegasi es la innovación métrica de su propuesta, que, al fin y al cabo, supone abordar un asunto solemne (regio) en seguidillas compuestas. Temeroso ante la posible reacción de los lectores, amantes de los cauces populares pero reticentes ante cualquier ruptura del decoro, los advierte de su elección, al tiempo que la justifica con las siguientes palabras:

\footnotetext{
En tan reducidas hojas observarás, si lo adviertes, seguidillas, que son fuertes porque son fuertes las flojas. Si de equívocos te enojas, disimulándolos vamos,
}

50. La obra está dedicada al marqués de Estepa, conde de Fuensalida y de Barajas, y al final de esta (s/n) se incluye el soneto "Venid con bien a nuestro patrio nido", de alabanza a los nuevos monarcas.

51. Descripción festiva, dedicatoria al conde de Fuensalida y de Barajas (s/n). 
pues hombres que veneramos

los usan (y se usarán).

En fin, como hijos de Adán, todos nos equivocamos ${ }^{52}$.

Finalmente, incluye Benegasi entre los paratextos el diálogo en octavas jocosas que se anunciaba en la portada, en el que plantea un ficticio intercambio verbal entre él mismo y la musa Talía ${ }^{53}$. En este texto el autor vuelve a insistir en la problemática del cauce poético elegido. A pesar de que es habitual en Benegasi el uso del arte menor, en cuyos metros encuentra el cauce formal más adecuado para su estilo jocoserio, en esta ocasión, dada la naturaleza solemne del asunto abordado, el autor, a pesar de su dilatada trayectoria, vuelve a hallarse en la misma situación de inseguridad y vulnerabilidad en la que se encontraba cuando entrega a la imprenta su primera vida de santo contada en metros populares. En el complejo proceso de autojustificación desarrollado por Benegasi en estas octavas introductorias, podemos encontrar un doble y ambiguo movimiento que va desde la autoinculpación ("Pero si te vences a los legos, / ¿quién más lego?, ¿quién más que Benegasi?») ${ }^{54}$ a la autodefensa. Este juego de tensiones, que acabará constituyéndose en un mecanismo característico del autor en esta etapa, parece tener su origen en la asunción de las críticas ajenas como defectos propios. Así lo vemos en el siguiente fragmento:

Talia: Ya te dicté bastantes redondillas, ya de llamarme no es razón que trates. Déjate ya de hacer más seguidillas, antes que den contigo en los orates. Ya tienes trabajadas mil obrillas que te han costado penas y debates; de ellas las librerías están llenas.

No prosigas en más y haz obras buenas. [...]

Autor: Pero porque en los cantos no tropieces, por si devota en ellos empezabas, dándote a octavas, no, por ahí no empieces, que eres bellaca, mucho, para octavas. A un metro alegre quiero te endereces, tañéndome la lira que pulsabas;

52. Descripción festiva, prólogo $(\mathrm{s} / \mathrm{n})$.

53. La alusión a esta musa en una composición en octavas nos remite directamente al ejemplo del Polifemo gongorino ("Estas que me dictó rimas sonoras / culta, sí, aunque bucólica, Talía»), referente para nuestro autor en su transgresora propuesta.

54. Descripción festiva, fragmento del diálogo jocoso (s/n). 
lo heroico quede al que hace maravillas.

Talía: ¿Pues qué quieres te dicte? Autor: Seguidillas.

Que cuando el gozo a todos nos rebosa

y un rey tan español nos ha venido, metros del Tasso fuera gastar prosa, y el que es rey justo quiere lo ceñido. Es decir mucho en poco linda cosa; es decir poco en mucho, aborrecido. Y aunque son seguidillas, los capaces las saben apreciar si tú las haces ${ }^{55}$.

En definitiva, en la Descripción festiva Benegasi aprovecha una circunstancia histórico-social de relieve que le permite recrear las ya superadas circunstancias de autor-criado -al menos, desde su autoconcepción como autor profesionalpara dar lugar a un texto muy personal en el que están presentes las características fundamentales de su literatura, ya sublimadas en esta etapa y que a estas alturas constituyen lo que pudiéramos denominar un indiscutible sello personal (metro popular, estilo jocoserio), que en esta obra encuentra, a nivel formal, en el ripio y las asonancias, y a nivel conceptual, en la ironía, la burla y lo chocarrero, unas herramientas propias que el autor utiliza con una soltura sin precedentes. A estos recursos se suma una suerte de sinceridad derivada del constante uso de la primera persona y las continuas alusiones al yo autorial. Así pues, en este texto Benegasi consigue investirse en una suerte de bufón al servicio de nadie que recurre a la tradicionalmente inofensiva literatura de circunstancia para crear un texto muy controvertido y de mayor complejidad de la que aparenta. Con él logra subvertir la naturaleza habitual del género convirtiendo la fiesta en honor de los reyes en una ocasión perfecta para la sátira de costumbres y, en un giro de una enorme modernidad, en una autosátira que persigue poner patas arriba incluso su propia identidad como poeta y, desde luego, como poeta que merece ser publicado.

Tan solo unos meses después de la publicación de la Descripción festiva ${ }^{56}$ se imprime Papel nuevo: Benegasi contra Benegasi ${ }^{57}$, una obra en la que el autor dice defenderse de las críticas recibidas por su descripción de las fiestas. Sin embargo, no hemos hallado ninguna polémica al respecto en la prensa de la época, ni en el Diario de los literatos, que solía hacerse eco de la mayor parte de los enfrentamientos literarios de la época, ni en los anuncios de la Gaceta de Madrid ${ }^{58}$, donde

55. Ibidem.

56. Esta debió de producirse poco después de las fiestas, celebradas en julio de 1760.

57. Estudio esta obra con mayor profundidad en Padilla Aguilera, Tania. "Papel nuevo. Benegasi contra Benegasi. La autoafirmación como estrategia de mercado", 2020. (En prensa).

58. Estos han podido ser consultados gracias a la base de datos NICANTO, a cargo del profesor Jean-Marc Buiguès de la Université Bordeaux Montaigne, quien ha tenido la amabilidad de aportarme algunos datos históricos y documentos de gran relevancia en el desarrollo de este artículo. 
habrían constado los papeles salidos de las prensas en relación con este supuesto enfrentamiento. Es posible que no se haya conservado la documentación al respecto, o que las críticas le llegaran al autor por vía oral, pero también cabe la posibilidad de que Benegasi, avisado por anteriores experiencias no muy positivas, escribiera este papel a la manera de vacuna con la que inocularse una pequeña dosis de autocrítica -como, por otra parte, venía siendo habitual en él- que lo inmunizara ante las críticas que pudiera recibir a causa de las singulares características de su obra. En este sentido, el poeta se ve obligado a excusar la escritura de este papel aludiendo a unas supuestas críticas que justifiquen su existencia, ya que no parece que pecar de receloso pudiera ser conveniente a su propósito.

En Benegasi contra Benegasi hallamos, pues, una obra en la que el autor plantea, de manera similar al diálogo en octavas con la musa Talía que precedía a la Descripción, un desdoblamiento dialéctico en el que, en esta ocasión, el Benegasi autor se enfrenta a un supuesto Benegasi crítico que, a diferencia de los que suelen "tirar» contra su obra, según el autor, movidos por la envidia, persigue tratarla de manera ecuánime. Sin embargo, el poeta es consciente de las deficiencias de su propuesta y, como no podía ser de otra manera conocido su celo, no duda en plantear la cuestión en unas décimas incluidas en los preliminares:

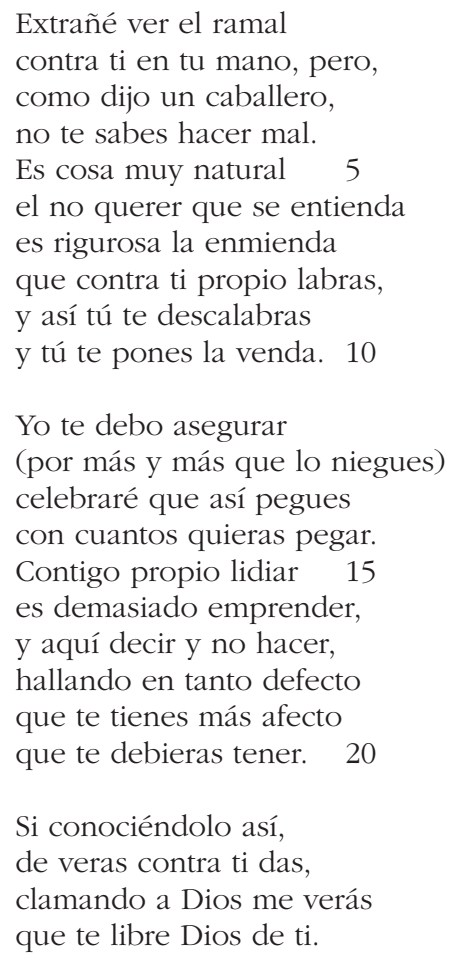


En cuanto dices aquí 25

más de un reparo se ofrece.

Nueva crítica merece,

pues, visto con reflexión,

parece tener razón

y la razón no parece ${ }^{59}$. 30

De esta manera, en Benegasi contra Benegasi el autor acaba extendiendo a toda la obra el beligerante tono usado en los paratextos para construir un discurso preponderantemente metaliterario en el que abundan las paradojas y contradicciones. A lo largo de todo el texto, Benegasi arremete ferozmente contra la figura del crítico y, también siguiendo en esto el ejemplo de su admirado Lope, convirtiendo al lector en el juez más capacitado y en el destinatario más cualificado para juzgar su obra. Esta idea del imperio del lector/comprador es planteada ya desde los inicios del discurso:

Tal cual a tu tribunal
va la obrilla, oscura o clara,
pero yo me contentara
como ella fuera tal cual.
Haz examen especial
de todos sus versos flojos,
paralíticos y cojos;
mira que se ha de exponer
donde todos la han de ver,
y no todos con tus ojos ${ }^{60}$.

En cualquier caso, tanto si Benegasi considera necesaria la publicación de esta obra para defenderse de una serie de críticas ya recibidas que circularan impresas, manuscritas o entre los círculos literarios de la época, como si lo que pretende es anticiparse, como le ocurre ya desde los propios preliminares de la Descripción, a una posible recepción negativa, principalmente por parte de esos críticos a los que tanto parece temer, lo que parece evidente es que con esta obra nuestro poeta conquista al fin y de manera absoluta su lugar en el campo literario. De nuevo, es en la portada donde encontramos una serie de claves fundamentales:

59. Benegasi contra Benegasi, prólogo (s/n), pp. 5v.-6r. de la edición modernizada que elaboré en 2015 para la web de Phebo.

60. Benegasi contra Benegasi, pp. 3-4, pp. 7v.-8r. de la edición de la web de Phebo. 


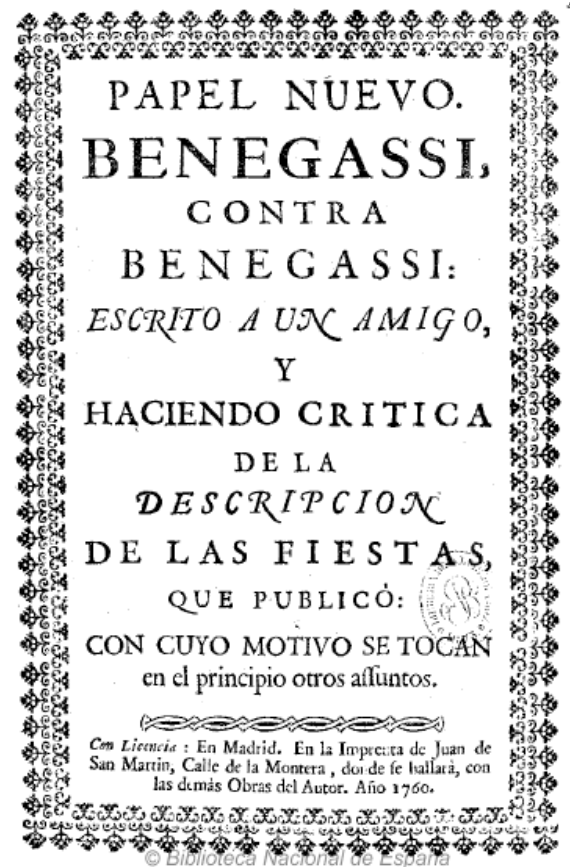

Portada de Papel nuevo: Benegasi contra Benegasi. Madrid, 1760.

Como vemos, el primer apellido del autor figura solo, esto es, sin acompañarse del nombre, del segundo apellido ni de las habituales credenciales, por duplicado y conquistando el lugar del título. Además, el tamaño de la tipografía subraya la relevancia del autor en este caso. Benegasi fue un poeta al que siempre le gustó poner el foco sobre sí mismo ${ }^{61}$, bien generando un discurso testimonial, preponderantemente basado en una actitud en apariencia sincera, bien pasando los hechos por un continuo tamiz subjetivo en el que la propia opinión siempre estaba presente. En este caso, plantea un enfrentamiento dialéctico consigo mismo del que, pese a las críticas que se autoinflige, es imposible que salga mal parado, puesto que ha decidido colocar su persona en todas las categorías posibles del texto: el tema, el argumento, el autor y el receptor. Incluso en este caso el pie de imprenta coadyuva al autopanegírico. En él podemos leer que la obra se puede adquirir «en la imprenta de Juan de san Martín, calle de la Montera, donde se hallará, con las demás obras del autor». Aunque no es la primera vez que encontramos en la portada de la obra una referencia explícita al corpus del autor, a

61. Es muy habitual encontrar su apellido en posición de rima en sus versos, pese a las dificultades que, como es lógico, plantea. 
estas alturas de su trayectoria literaria y dada la singular naturaleza de este texto, que tiene como referente un texto anterior, la alusión aquí contribuye claramente al éxito de esta inteligente maniobra editorial que, pergeñada o no por el propio Benegasi, constituye un órdago muy singular a estas alturas de la carrera literaria de nuestro autor.

En definitiva, sea cual sea la razón por la que Benegasi publica esta beligerante obrita, tanto por su extensión como por su tono constituye el epítome de la actitud de este autor -inestable y contradictoria, en perpetua tensión dialécticaante la literatura: entre el diletantismo y la profesionalidad, entre la sinceridad y la máscara, entre la autocrítica y la autodefensa.

Como apuntamos más arriba, la posterior ordenación sacerdotal de Benegasi, ya en los últimos días de su vida, contribuirá, al igual que también sucedió con Lope de Vega, a incrementar la aparente impronta de sinceridad que caracteriza a esta etapa de su producción. Esto irá unido a un continuado éxito de recepción, lo que se reflejará en las numerosas reediciones, principalmente de las vidas de santos, que aparecen en la década de los 70 e incluso en fechas posteriores ${ }^{62}$.

Tras este somero recorrido por la trayectoria de las obras impresas de José Joaquín Benegasi y Luján, podemos afirmar que nos encontramos ante un autor cuyo poliédrico perfil exige un estudio en profundidad de las diferentes facetas de su vida y de su obra.

Ya desde su juventud Benegasi decide abandonar la actitud amateur a la que parecía estar llamado por su condición de miembro de la baja nobleza para iniciar una carrera literaria a la que se incorpora bajo la máscara que le brindan los seudónimos o la anonimia, que, bien empujado por el cambio de la legislación, bien por la conquista de una posición identificable en el campo literario, solo volverá a recuperar en la edición de aquellas obras de las que preferirá desvincularse. La necesidad de la búsqueda de mecenazgo lo lleva a entregar a la imprenta las primeras obras firmadas, en las que junto al nombre incorpora unas no muy pomposas credenciales que le acompañarán durante toda su vida. La figura de su padre, el dramaturgo Francisco Benegasi, desempeñará un papel fundamental en la carrera del autor, tanto a la hora de establecer sus primeros contactos en el campo literario, como, una vez fallecido, al brindarle la ocasión de convertirse en depositario - por herencia familiar, pero también estética- de su célebre apellido.

Poco a poco irá Benegasi adquiriendo su propia voz, que encontrará en el arte menor y el estilo jocoserio sus principales credenciales. Esto lo colocará en la compleja situación -ante la que estaba aparentemente atormentado- de ofrecer

62. Sin embargo, a finales de la década de los 80 comienza a diluirse la firma del autor en relación con algunas de sus producciones. A este respecto, véase la nota 16. 
una mirada diferente en el tratamiento de textos solemnes como hagiografías u homenajes. Su particular idea de la literatura, que lo encuadra sin duda en una mentalidad profesional del hecho literario, lo lleva a transformar textos circunstanciales o la literatura "de encargo» (descripciones, epístolas, pronósticos) en propuestas literarias de una enorme originalidad.

Sin embargo, es en las obras que podrían clasificarse en el periodo que hemos denominado de senectute donde encontramos un mayor grado de originalidad e independencia. En ellas Benegasi incrementa en su discurso, de un lado, la sinceridad -abundan las referencias personales y a hechos concretos de su vida- y, de otro, la presencia de lo metaliterario, que plantea la continua defensa de una voz propia en un entorno intelectual que se plantea-que él plantea-como particularmente hostil y en el que, paradójicamente, Benegasi utiliza algunos de los calificativos de sus detractores - poeta lego o rudo- para posicionarse. Además, en esta etapa el autor desarrolla con soltura estrategias editoriales claramente orientadas hacia un propósito comercial o de autopromoción con las que persigue insertarse en la red de sociabilidad que conforma la república literaria de su tiempo, sin perder de vista la manera en que su ya ingente obra y su particular perfil literario pueden encajar en una noción de canon en la que son los lectores/ compradores quienes tienen la última palabra.

En definitiva, la trayectoria editorial de José Joaquín Benegasi y Luján constituye en sí misma un ejemplo del camino que vive la literatura española entre los siglos XVII y XVIII desde el amateurismo académico y las tradicionales relaciones de mecenazgo, hasta el nacimiento de la profesionalización y las modernas estrategias de mercado.

\section{BiBliografía}

\subsection{Impresos del autor citados en este artículo}

ANónima. Comedia (que no lo es) burlesca, intitulada Llámenla como quisieren. Su autor ella lo dirá. Y se hallará donde la encuentren, y será en la imprenta y librería de Juan de san Martín, calle del Carmen, donde se hallarán otros papeles curiosos escritos por el mismo autor. En Madrid: Juan de San Martín.

ANónima. Comedia (que no lo es) burlesca, intitulada Llámenla como quisieren. Su autor ella lo dirá, y por si lo calla: don José Joaquín Benegasi y Luján, etc. Se incluye al fin de ella el sainete de El Amor casamentero. Segunda impresión. En Madrid: en la imprenta de Francisco Javier García, calle de los Capellanes. Se hallará en la librería de José Matías Escribano, frente a las gradas de San Felipe el Real. 1761 [reedición].

ANóNIMA. Con el motivo de haber pasado a mejor vida [...] don Francisco Fernández de la Cueva, duque de Alburquerque [...]. Escribía para eterna memoria de su elevadísimo mérito don José Joaquín Benegasi y Luján este soneto. 1757 (?).

ANÓNIMA. Con el motivo del nuevo concordato ajustado con la corte romana escribía don José Benegasi y Luján el siguiente soneto. Madrid. Las obras líricas de este autor se hallarán en la librería del Mercurio, 1753 (?). 
ANÓNIMA. Con el motivo del terrible temblor de tierra sucedido en el día de Todos los Santos de este año de 1755 escribió don José Joaquín Benegasi y Luján a su amigo el reverendo padre fray Juan Carrasco, religioso trinitario calzado, el siguiente soneto. En Madrid, en la imprenta y librería de José García Lanza, 1755.

AzPITARTE, Juan Antonio. Carta en prosa y en diferentes metros, en la que se incluye un sueno breve, a fin de que vuelva de un letargo cierto ingenio místico, esto es, dado a Dios. Escribiala a un pariente suyo Juan Antonio de Azpitarte, y la da a luz quien, aunque no corre con el autor, anda con él. En Madrid, se hallará en la imprenta y librería de Juan de San Martín, 1744 (?).

AZPITARTE, Juan Antonio. Carta en respuesta de otra, que le habia escrito un amigo noticiándole cierto desengaño de una parienta. 1747 (?).

Benegasi y Luján, José Joaquín. Al señor don Juan Francisco Gaona y Portocarrero, conde de Valparaíso, marqués de Añavete, caballero de la orden de Calatrava, comendador de Gallizuela de Ladres en la Alcántara, del consejo de Su Majestad en el supremo de Indias, primer caballerizo de la reina nuestra señora, secretario de Estado y del despacho universal de la real Hacienda, superintendente general de rentas, con el manejo $y$ distribución de caudales, y presidente de las juntas de comercio y tabaco, escribia, con el motivo que en él se expresa, su más respetuoso apasionado, don José Joaquín Benegasi y Luján, este romance. 1754 (?).

D. J. B. y L. Definición del mundo, de la hermosura, de la nobleza y del aplauso hecha en un romance mistico, por D.J.B. y L. En Madrid: se hallará en la imprenta y librería de Juan de San Martín.

D. J. B. y L. Descripción del terremoto según se experimentó en la villa de Herencia el día 1 de noviembre de este año de 1755 a las diez del día. Compuesto a impulsos del desengaño, para mayor escarmiento, por don José Joaquín Benegasi y Luján en estas endechas endecasílabas. En Madrid: en la oficina de José de Orga, impresor, calle de Bordadores, junto a la Casa Profesa. Se hallará en la librería de José Orcel, a la entrada de la calle de la Montera. 1755.

D. J. B. y L. Descripción festiva de la suntuosa carrera y reales funciones con que esta imperial y coronada villa ha celebrado la plausible entrada y exaltación al trono de nuestros católicos monarcas, los señores don Carlos III y doña María Amalia, en los días 13, 14, 15 y 19 de julio de este año de 1760. Escribiala en seguidillas y con la introducción en octavas jocosas don José Joaquín Benegasi y Luján. En Madrid: en la imprenta de Miguel Escribano, en la librería de José Matías Escribano [...], 1770 (?).

PAZ y MONROY, Joaquín de. El no se opone de muchos y residencia de ingenios. Su autor don Joaquín de Paz y Monroy. Madrid: Se hallará en la tienda de don Francisco Romero,1739 (?).

Paz y Monroy, Joaquín de. Fama póstuma del reverendísimo padre fray Juan de la Concepción, escritor de su sagrada religión de carmelitas descalzos, calificador de la Suprema, secretario general, consultor del serenísimo señor infante cardenal, de la Real Academia de la Lengua Española, etc. Escribiala en octavas don José Joaquín Benegasi y Luján, regidor perpetuo de la ciudad de Loja, etc. También se incluye el célebre poema que compuso dicho reverendísimo con el título de Escuela de Urania y un indice de varias obras suyas, impresas y manuscritas, etc. Se dedica a mi señora doña Raimunda Bienpica y Sotomayor, etc. Madrid: en la imprenta del Mercurio, por José de Orga, impresor. Se hallará en casa de don Francisco González Clemente, frente de la cárcel de la corte, y los otros dos papeles que se previenen en el índice, 1754. 
PAZ Y MONROY, Joaquín de. Obras líricas jocoserias que dejó escritas el señor don Francisco Benegasi y Luján, caballero que fue del orden de Calatrava, gobernador y superintendente general de Alcázar de San Juan, Villanueva de los Infantes y Molina de Aragón, del consejo de Su Majestad, en el de Hacienda, regidor perpetuo de la muy noble ciudad de Loja, patrono de la capilla que en el real monasterio de san Jerónimo de esta corte fundó la señora doña María Ana de Luján, etc. Van añadidas algunas poesías de su hijo, don José Benegasi y Luján, posteriores a su primer tomo lírico, las que se notan con esta señal*. En Madrid: en la oficina de Juan de San Martín y a su costa; se hallará en su librería, calle de la Montera, donde se vende el Mercurio, 1746.

PaZ y Monroy, Joaquín de. Panegírico de muchos, envidiados de no pocos. Su autor don José Joaquín Benegasi y Luján, señor de los Terreros y Valdeloshielos, regidor perpetuo de la ciudad de Loja y patrono de la capilla que en el real monasterio de san Jerónimo de la corte fundó la señora doña Mariana de Luján. En Madrid, en la oficina de José de Orga, impresor, calle de Bordadores, junto a la Casa Profesa. Se hallará en la librería de José Orcel, a la entrada de la calle de la Montera, 1755.

PAZ y MONROY, Joaquín de. El no se opone de muchos y residencia de ingenios. Escribíale en prosa y metros diferentes don José Joaquín Benegasi y Luján. Tercera impresión, habiendo salido la primera con el segundo nombre y otro apellido del autor. En Madrid: en la imprenta de Miguel Escribano. Se hallará, con otras obras del autor, en la librería de José Matías Escribano, frente a las gradas de San Felipe el Real, 1761 (?).

Edición modernizada a cargo de Pedro Ruiz Pérez. Phebo, Universidad de Córdoba, 2015 [En línea] http://www.uco.es/investigacion/proyectos/phebo/sites/default/files/panegirico_de_muchos.pdf.

Papel en prosa y diferentes metros celebrando los sobresalientes talentos, elevadas prendas $y$ acertadísima conducta de nuestro soberano. Escribíale al señor marqués de la $\mathrm{Ol}$ meda, comendador de Villarrubia de Ocaña, en la orden de Santiago, etc., su antiguo apasionado don José Joaquín Benegasi y Luján, señor de los Terreros y Valdeloshielos, regidor perpetuo de la ciudad de Loja. En Madrid: por José Orga, 1755.

Papel en prosa y diferentes metros celebrando los sobresalientes talentos, elevadas prendas y acertadísima conducta de nuestro soberano. Escribiale al señor marqués de la $\mathrm{Ol}$ meda, comendador de Villarrubia de Ocaña, en la orden de Santiago, etc., su antiguo apasionado don José Joaquín Benegasi y Luján, señor de los Terreros y Valdeloshielos, regidor perpetuo de la ciudad de Loja. En Madrid: en la imprenta de Miguel Escribano, calle Angosta de san Bernardo. Se hallará este papel y otro del mismo autor intitulado Rasgo métrico en las librerías de José Matías Escribano y en la de Juan Pérez, frente de San Felipe el Real, 1760 (?) [reedición].

Papel nuevo. Benegasi contra Benegasi, escrito a un amigo y haciendo crítica de la descripción de las fiestas que publicó, con cuyo motivo se tocan en el principio otros asuntos. En Madrid: en la imprenta de Juan de San Martín, calle de la Montera, donde se hallará con las demás obras del autor, 1760.

Edición modernizada a cargo de Tania Padilla Aguilera. Phebo, Universidad de Córdoba, 2015 [En línea] http://www.uco.es/investigacion/proyectos/phebo/sites/default/files/ benegasi_contra_benegasi.pdf.

Poesías líricas y jocoserias. Su autor don José Joaquín Benegasi y Luján, señor de los Terreros $y$ Valdeloshielos, regidor perpetuo de la ciudad de Loja, quien las dedica al excelentísimo señor marqués de Villena, duque de Escalona, conde de San Esteban de Gormaz, 
caballero del insigne orden del Toisón, etc. En Madrid: en la imprenta de José González; vive en la calle del Arenal, 1743.

Rosal, Juan del. Pronóstico el más cierto y más breve que en estilo jocoso bace del nuevo cometa don Juan del Rosal en este romance. Madrid: Se hallará en la imprenta y librería de Juan de San Martín, calle del Carmen.

Rosal, Juan del. Vida del portentoso negro san Benito de Palermo, descrita en seis cantos, jocoserios, del reducidísimo metro de seguidillas, con los argumentos en octavas, por don José Joaquín Benegasi y Luján. En Madrid: en la imprenta de Juan de San Martín. Se hallará en su librería, calle de la Montera, con las demás obras del autor, 1750.

Rosal, Juan del. Vida del portentoso negro san Benito de Palermo, descrita en seis cantos jocoserios, del reducidísimo metro de seguidillas, con los argumentos en octavas, por don José Joaquín Benegasi y Luján. Con licencia en Madrid y reimpreso en el Puerto de Santa María, por Francisco Vicente Muñoz, impresor mayor de la ciudad, y se hallará en su librería, en la calle de Luna, 1752 [reedición].

Rosal, Juan del. Vida del portentoso negro san Benito de Palermo, descrita en seis cantos jocoserios, del reducidísimo metro de seguidillas, con los argumentos en octavas, por fray don José Joaquín Benegasi y Luján, canónigo reglar de nuestro gran padre san Agustín, del hábito de san Antonio Abad. En Madrid: en la imprenta de Miguel Escribano, calle Angosta de San Bernardo. Se hallará, con otras obras del autor, en la librería de José Matías Escribano, frente de San Felipe el Real. 1763 [reedición].

Rosal, Juan del. Rasgo métrico [...] en la llorada muerte [...] de Fernando el VI. Escribía don José Joaquín Benegasi y Luján [...]. Madrid: Se hallará en las librerías de José Matías Escribano y en la de Juan Pérez, frente de San Felipe el Real, 1759 (?).

Rosal, Juan del. Respetuosa súplica que a la reina madre, nuestra señora, hace en un romance lírico don José Joaquín Benegasi y Luján, regidor perpetuo de la ciudad de Loja. En Madrid: en la imprenta de Antonio Marín. Se hallará en la librería de Juan Pérez, frente de San Felipe el Real.

Rosal, Juan del. Romance heroico y glosa de una quintilla que con el motivo de la justamente llorada pérdida de nuestra augusta soberana, la señora doña María Amalia de Sajonia, escribía don José Joaquín Benegasi y Luján. Madrid: en la imprenta de Manuel Martín, calle de la Cruz, 1760.

Rosal, Juan del. Vida de San Dámaso, Pontífice [...], escrita en estilo jocoserio.

Rosal, Juan del. Vida del glorioso san Dámaso, pontífice máximo, martillo de la herejía, diamante de la fe, crisol de la castidad y especialísimo abogado de los perseguidos con falsos testimonios. Escribiala en redondillas jocoserias fray don José Joaquín Benegasi y Luján, canónigo reglar de nuestro gran padre san Agustín, del hábito de san Antonio Abad, en su real casa de esta corte. Sale aumentada y corregida en esta segunda impresión por el mismo autor. En Madrid: en la imprenta de Miguel Escribano, calle Angosta de san Bernardo. Se hallará, con otras obras del autor, en la librería de José Matías Escribano, frente de San Felipe el Real, 1763 [reedición].

Rosal, Juan del. Vida del portentoso negro san Benito de Palermo, descrita en seis cantos jocoserios, del reducidísimo metro de seguidillas, con los argumentos en octavas, por fray don José Joaquín Benegasi y Luján, canónigo reglar de nuestro gran padre san Agustín, del hábito de san Antonio Abad en su real casa hospital de esta corte. En Madrid: en la imprenta de don Antonio Pérez de Soto, impresor de la Real Biblioteca. A costa de la Real Compañía de Impresores y Libreros del Reino, 1779 [reedición]. 


\subsection{Obras contemporáneas}

Aguilar PIÑal, Francisco. Bibliografía de autores españoles del siglo XVIII. Madrid: CSIC, tomo I, 1981.

Aguilar Piñal, Francisco. Madrid en tiempos del «mejor alcalde». Sant Cugat (Barcelona): Editorial Arpegio, volumen 3, 2016.

AA. VV. Correo de Madrid (números 50 a 422). Madrid: Biblioteca Digital Hispánica, 17871791. [En línea] http://hemerotecadigital.bne.es/details.vm?q=id:0003752667.

AA. VV. Diario de los literatos: en que se reducen a compendio los escritos de los autores españoles, y se hace juicio de sus obras. Madrid: Biblioteca Digital Hispánica, 1737-1742. [En línea] http://bdh-rd.bne.es/viewer.vm?id=0000014531\&page=1.

AA. VV. Diario curioso, erudito, económico y comercial (Diario de Madrid), tomo III, enero-marzo, 1787. Madrid: imprenta de Manuel González.

AA. VV. Gaceta de Madrid. Madrid: Base de datos NICANTO. Université Bordeaux Montaigne, 1697-1934.

AA. VV. Memorial literario instructivo y curioso de la corte de Madrid (vol. 17), julio de 1789, parte primera, n. ${ }^{\circ}$ Ixxxix. Madrid: Biblioteca Digital Hispánica, 1789. [En línea] http://hemerotecadigital.bne.es/issue.vm?id=0012147587.

AA. VV. Novísima recopilación de las leyes de España dividida en XII libros en que se reforma la recopilación publicada por el señor don Felipe II en el año de 1567, reimpresa últimamente en el de 1775 [...], libro VIII. Madrid: Agencia Estatal, BOE (2019), 1805.

Bourdieu, Pierre. Las reglas del arte: génesis y estructura del campo literario. Barcelona: Anagrama, 2006.

Ferreira Prado, María Cecilia y Servera BaÑo, José. «José Joaquín Benegasi: de la poética popular y la poesía barroca a la autobiografía de un "novator"”. Dieciocho, 2018, 41.1, Spring, pp. 107-130.

Foucault, Michel. "QQué es un autor?». Boletín de la Sociedad Francesa de Filosofía, 1969, año 63, n. $^{\circ} 3$, julio-setiembre.

GREENBLATT, Stephen. Reinassance self-fashioning: from more to Shakespeare. Chicago: University, 1984.

JIMÉNEZ BELMONTE, Javier. «Amateurs preclaros de la España postbarroca: nostalgias de un modelo socioliterarion. Caliope: journal of the Society for Renaissance and Baroque Hispanic Society, 2012, vol. 18, n. ${ }^{\circ}$ 1, pp. 78-101.

LEFEVERE, André. Traducción, reescritura y la manipulación del canon literario. Salamanca: Colegio de España, 1997.

López AlEMANY. "Un poeta en deuda: José Benegasi y Luján y el mecenazgo de Isabel de Farnesio». Dieciocho, 2019, 5 (Anejos), Fall, pp. 163-177.

Padilla Aguilera, Tania. "José Joaquín Benegasi y Luján (1707-1770): perfil vital». Cuadernos de Ilustración y Romanticismo: Revista del Grupo de Estudios del Siglo XVIII, 2019, n. ${ }^{\circ} 25$. (En prensa).

Padilla Aguilera, Tania. "Papel nuevo. Benegasi contra Benegasi. La autoafirmación como estrategia de mercado", 2020. (En prensa).

PALAU Y DUlCET, Antonio. Manual del librero hispano-americano; bibliografía general española e hispano-americana desde la invención de la imprenta hasta nuestros tiempos, con el valor comercial de los impresos descritos, tomo xiv. Barcelona: Librería anticuaria de A. Palau, 1962. 
ROZAS, Juan Manuel. «El ciclo de senectute». En Estudios sobre Lope de Vega. Madrid: Cátedra, 1990, pp. 73-133.

Ruiz Pérez, Pedro. "El sujeto autorial dieciochesco: a partir de una Fama póstuma». En LORENZO ÁlVAREZ, Elena de (coord.). Ser autor en la España del Siglo XVIII. Gijón: Ediciones Trea, 2017, pp. 479-508.

Ruiz PÉREz, Pedro. "Para una bibliografía de José Joaquín Benegasi y Luján. Hacia su consideración crítica». Voz y Letra: Revista de Literatura, 2012, vol. 23, n. ${ }^{\circ}$ 1, pp. 147-169.

Ruiz PÉREZ, Pedro. «Sentimental subjectivity and autorial subject: trajectory and three levels». En Özmen, Emre y Padilla Aguilera, Tania (coords.). El sujeto literario en la Monarquía Hispánica. Theory Now. Journal of Literature, Critique and Thought, 2019, n. 2. STROSETZKI, Christoph. La literatura como profesión (En torno a la autoconcepción de la existencia erudita y literaria en el Siglo de Oro español). Kassel: Reichenberger, 1997. 
